\title{
ASPECTOS LEGALES DE LA PUBLICIDAD EN TELEVISIÓN Y LA DEFENSA DE LOS DERECHOS DE LAS AUDIENCIAS
}

Pedro J. Reinares Lara. Departamento de Economía de Empresa; Área de Comercialización e Investigación de Mercados. Facultad de Ciencias Jurídicas y Sociales. Universidad Rey Juan Carlos. C/ Paseo de los Artilleros, s/n.

Vicálvaro.28032 Madrid.E-mail:pedro.reinares@urjc.es.

Eva Marina Reinares Lara. Departamento de Economía de Empresa; Área de Comercialización e Investigación de Mercados. Facultad de Ciencias Jurídicas y Sociales. Universidad Rey Juan Carlos. C/ Paseo de los Artilleros, s/n.

Vicálvaro. 28032 Madrid. E-mail: eva.reinares@urjc.es.

\section{Resumen}

La comunicación publicitaria en televisión es parte fundamental en las estrategias de comunicación de los anunciantes, generando su elevado volumen de negocio complejas relaciones entre los agentes participantes. Este artículo presenta una interpretación del marco legal que regula los formatos publicitarios en televisión fundamentada en los procedimientos habituales del mercado. El análisis aplicado es resultado de una investigación sobre la adecuación de la normativa a las figuras reguladas y sus equivalentes en los formatos comerciales de las cadenas, interpretando el grado de cumplimiento de los fines perseguidos por dicha normativa y en especial en la defensa de los derechos de las audiencias.

\section{Palabras clave}


Publicidad en televisión; Formas de publicidad no convencional; Marco legal de la publicidad en televisión; Directiva de la "Televisión sin Fronteras.

\section{Abstract}

The television advertising is a fundamental part in the communication strategies of clients. The important revenues that are generated develop complex relationships between the agents involved. The article presents an interpretation of the regulatory framework for Spanish TV broadcasting formats. The research carried out is the result of a criticism investigation about the adjustment of the legal frame to the different figures regulated and its equivalent on the chain's commercial formats, interpreting the level of compliment of the goals targeted, especially in the defense of the audience's rights.

\section{Key words}

Television advertising; Non conventional forms of advertising; Legal framework of broadcast advertising; Audiovisual Media Services without frontiers Directive.

\section{INTRODUCCIÓN}

La utilización del medio televisión como soporte publicitario puede analizarse desde diferentes perspectivas (económicas, sociológicas, legales, comunicacionales) que reflejan su influencia mucho mas allá de los ámbitos propios del marketing. Como instrumento de comunicación persuasiva, sus efectos sobre las audiencias y sus implicaciones éticas, han sido objeto de una gran concienciación social, cuyo reflejo último se manifiesta en leyes reguladoras específicas para el medio televisión aparentemente más estrictas que para el resto de los medios. Una de las funciones principales de las diferentes normativas concernientes a la publicidad es proteger los derechos básicos de los consumidores transformados en audiencias al recibir los mensajes publicitarios. Si bien existe una normativa que regula la publicidad en sus principales formas y a través de todos los medios, razonablemente adecuada para los formatos más consolidados, conocidos como publicidad convencional, el dinamismo del mercado ha favorecido el reciente desarrollo de nuevas formas de comunicación persuasiva que utilizan, en algunos casos, diferentes y complejos subterfugios para evadir el cumplimiento de la normativa vigente. Sus potenciales efectos 
sobre la modificación de la conducta de las audiencias han sido objeto de elementos restrictivos o al menos reguladores por las sucesivas actualizaciones de las normativas.

El interés de los aspectos legales de la publicidad queda reflejado en la bibliografía específica sobre comercialización, comunicación y publicidad. No obstante, se evidencia una carencia de estudios que versen sobre la adecuación de la normativa a los fines perseguidos, la correcta conceptualización de los elementos regulados para evitar vacíos legales y, en especial, el grado de desarrollo objetivo que estos formatos tienen en el actual mercado publicitario de televisión. En este sentido, una revisión de la literatura más reciente denota ciertas limitaciones que conducen a la necesidad de una justificación especifica del objeto de este artículo: algunas publicaciones al ser adaptaciones de libros foráneos desarrollan los aspectos legales a partir de normativas de otros países, sin bien los aspectos a proteger por dicha legislación son fundamentalmente los mismos, la información que proporcionan no es suficiente para entender las particularidades e implicaciones de la regulación del mercado publicitario español. Por otro lado, en otras publicaciones se limitan a enumerar el conjunto de normativas relacionadas con la comunicación publicitaria sin realizar una verdadera profundización en sus aspectos más operativos y en especial en aquellos más polémicos y dinámicos surgidos de la publicidad televisiva.

Finalmente, esta es una normativa en continua interpretación por las necesarias matizaciones que deben hacerse para delimitar la flexibilidad de las cadenas de televisión a la hora de interpretar de forma creativa aquellos aspectos más ambiguos de la legislación. Por todo ello, parece oportuno profundizar en la interpretación de todo aquel aspecto legal relacionado con la publicidad en televisión.

La publicidad por televisión se encuentra regulada en España de modo específico por la Ley 22/1999, de 7 de junio, que incorpora al ordenamiento jurídico español la Directiva 97/36/CE sobre la coordinación de disposiciones legales, reglamentarias y administrativas de los estados miembros relativas al ejercicio de actividades de radiodifusión televisiva. La mencionada norma supone la modificación de Ley 25/1994, de 12 de julio por la que se incorporaba al Ordenamiento Jurídico Español la Directiva 89/552/CEE.

Esta previsto que esta Ley vuelva a ser modificada de nuevo antes del año 2010, como consecuencia de la incorporación al ordenamiento jurídico de los estados miembros de la 
Unión Europea de la nueva Directiva Comunitaria aprobada el 24 de mayo de 2007 y que debe ser ratificada en la Eurocámara durante el mes de julio de 2007.

Dichas Directivas vienen siendo conocidas como "Ley de Televisión sin Fronteras". Evidentemente, esa voluntad armonizadora ha venido encontrando ciertas dificultades en la práctica. Dificultades en gran parte derivadas de las diferencias sociales, culturales, de mercado y de tradición legal entre los diferentes países comunitarios ${ }^{2}$.

Hay que tener en cuenta que las Directivas reconocen a los Estados miembros la facultad de introducir criterios propios y diferenciales a la hora de incorporar la norma al ordenamiento jurídico de cada país. Esta facultad se orienta, en la mayoría de los casos, a la posibilidad de establecer criterios de regulación más restrictivos, convirtiendo así a la norma europea en un texto de mínimos.

La nueva Directiva que debe ratificarse en el mes de julio de 2007 en la Eurocámara reconoce además el principio de país de origen, lo que significa que se aplicarán las reglas del país en el que está situado el proveedor de los servicios audiovisuales, y a pesar de la intención de la Eurocámara y de la Comisión Europea de hacer obligatoria la creación de organismos reguladores independientes al Gobierno y a las televisiones en los 27 Estados miembros, la nueva norma se refiere a ellos, simplemente, como entidades opcionales que pueden tener los países a la hora de informar a la Comisión de la aplicación de esta Directiva. Respecto al concepto de publicidad en televisión, la Ley española vigente 22/1999 ${ }^{3}$, de 7 de

\footnotetext{
${ }^{1}$ Lo que expresa claramente cuál era la voluntad inicial de la Comisión y del Parlamento Europeo al proceder a su aprobación: profundizar en la construcción del mercado único, consolidando una armonización normativa que permitiera que aquella actividad televisiva considerada legal en un Estado miembro lo fuera también, por los mismos criterios, en el resto de Estados. Esta armonización se expandió además a otros países europeos pertenecientes a la UE con la entrada en vigor de la modificación del Convenio Europeo de Televisión Transfronteriza. El 13 de Diciembre de 2005, la Comisión propuso la revisión de la Directiva 97/36/CE, ya aprobada el 24 de mayo de 2007, para atender a los considerables avances tecnológicos y a la evolución del mercado de servicios audiovisuales.

${ }^{2}$ Prueba de ello es el gran retraso sufrido en la elaboración de la modificación de esta norma común europea por la tremenda complejidad para armonizar realidades publicitarias muy diferentes adecuándose a prácticas comerciales habituales en el medio.

${ }^{3}$ Según establece la Directiva Comunitaria aprobada el 24 de mayo, esta Ley debe volver a ser modificada para su adaptación a la nueva Directiva antes del año 2010.
} 
junio (Art. 3), establece como condición general para considerar que un mensaje televisado cualquiera es publicidad por televisión: que sea emitido a cambio de remuneración o mediante contraprestación, por encargo de terceros en el marco de una actividad comercial, industrial, artesanal o profesional y con el fin de promover la contratación de bienes o servicios o bien determinadas actitudes y comportamientos entre los telespectadores.

De este modo, para el caso de la televisión, la publicidad se define de un modo más "procedimental" y menos intencional o finalista que en normas anteriores.

Al introducir la remuneración o la contraprestación como criterio para determinar el carácter publicitario de los mensajes televisivos, la normativa española actual:

- Dificulta el control sobre determinadas formas publicitarias que, por su propia naturaleza, no suelen contar con documentos contractuales como es el product placement.

- Permite la presencia de determinadas marcas y productos cuya publicidad estaría prohibida, pero que se mantienen en pantalla al no poder demostrarse el carácter publicitario de los mensajes en los que se inscriben.

- Impone en esos casos la carga de la prueba a los denunciantes de la posible ilicitud, ya sean usuarios o competidores; los cuales deberían demostrar fehacientemente la existencia de remuneración. En definitiva abre la puerta a prácticas publicitarias que pudieran ser calificadas como ilícitas o al menos alegales con una normativa más ajustada a las prácticas habituales del medio, como se evidenciará en los siguientes apartados de este trabajo.

Respecto a las obligaciones formales de la publicidad en televisión, las sucesivas Leyes 25/1994 y 22/1999, reconocen expresamente la vigencia en el medio televisivo de la Ley 34/1988, de 12 de noviembre, General de Publicidad, por lo que se refiere a la publicidad ilícita. En lo concerniente al análisis que nos ocupa, establece una cautela de identificabilidad, señalando la obligación de los medios de difusión de deslindar perceptiblemente la información de la publicidad, así como la obligación de los anunciantes de desvelar inequívocamente el carácter publicitario de sus anuncios (Art. 11).

Además de la ya mencionada obligación de identificabilidad, aplicada en este caso a la diferenciación con respecto a los programas a través de medios ópticos o acústicos (Art. 11.1), la Ley vigente señala los siguientes requisitos para la difusión de la publicidad por televisión: 
- Su limitación temporal. El tiempo total dedicado a la publicidad, con excepción de algunas formas, no podrá superar ni el 20\% del tiempo diario de emisión ni los 17 minutos $(12+5)$ por hora natural (Art. 13).

- Su emisión preferente entre los programas, pudiéndose ubicar dentro de los programas o interrumpiendo éstos siempre y cuando la interrupción no perjudique la unidad de dichos programas, ni se desmerezca el valor o calidad de éstos. Los bloques intraprogramas deberán estar separados por periodos de tiempo de 20 minutos como mínimo, aunque se admite por una sola vez dentro de cada programa que el lapso de tiempo entre dos bloques pueda ser inferior a ese tiempo pero no inferior a quince minutos (Art. 12.3).

- Su emisión entre las partes autónomas, intervalos o detenciones de un programa, siempre y cuando la estructura de éste cuente con dichos cortes programados o previstos (Arts. 12.1 y 2$)$.

- Su emisión en los momentos de menor interés, en el caso de acontecimientos continuos que no cuentan con intervalos de descanso (Art. 12.2).

- En el caso de los largometrajes cinematográficos y televisivos, se admite una interrupción publicitaria por cada periodo completo de 45 minutos de duración programada, autorizándose además otra interrupción si la duración total programada de la transmisión excede al menos en veinte minutos de dos o más de los períodos temporales iniciales citados.

- No podrá insertarse publicidad o televenta en la emisión de servicios religiosos ni en aquellos programas informativos, documentales, religiosos e infantiles cuya duración programada sea de 30 minutos o menos.

También se prohíbe la publicidad y la televenta encubiertas (Art. 9.2) ${ }^{4}$.

La Ley establece también limitaciones a la publicidad por televisión con el fin de proteger a los menores (Art. 16). De un modo genérico, se señala que la publicidad no contendrá

\footnotetext{
${ }^{4}$ Se entiende por tales aquéllas que suponen la presentación verbal, visual o sonora, dentro de los programas, de los bienes, los servicios, el nombre, la marca, la actividad o los elementos comerciales propios de un empresario que ofrezca bienes y servicios y que tenga, por intención del operador de televisión, propósito publicitario y pueda inducir al público a error en cuanto a su naturaleza. Se considera que existe propósito publicitario cuando su difusión se realiza, tal y como habíamos señalado más arriba, a cambio de remuneración, cualquiera que sea la naturaleza de ésta (Art. 3.d).
} 
imágenes o mensajes que puedan perjudicar moral o físicamente a los menores (Art. 16.1), sin establecer ninguna excepción con garantía, por ejemplo, de periodo horario de difusión, tal y como se hace en el caso de la programación.

Paradójicamente, la Ley establece con posterioridad (Art. 17) que la publicidad, en cualquiera de sus formas, que pueda perjudicar el desarrollo físico, mental o moral de los menores sólo podrá realizarse entre las 22:00 horas del día y las 06:00 horas del día siguiente, y deberá ser objeto de advertencia sobre su contenido por medios acústicos y ópticos.

A partir de este entorno legal aparentemente restrictivo, las cadenas de televisión encuentran numerosos vacíos legales o promueven interpretaciones favorables al desarrollo de la inclusión a lo largo de la programación de diferentes formatos publicitarios tremendamente creativos y en algunos casos de cuestionable legalidad. Con el tiempo estas prácticas se convierten en hechos consumados, que los organismos competentes y los mecanismos de autocontrol solo consiguen limitar parcialmente. En el punto 3 se describen los mas desarrollados, destacando sus implicaciones legales tanto para las cadenas como para las audiencias.

\section{OBJETIVOS Y METODOLOGÍA}

Este artículo tiene como objetivo principal valorar la adecuación de esta normativa legal a las figuras reguladas y sus equivalentes en los formatos comerciales de las cadenas, interpretando el grado de cumplimiento de los fines perseguidos por dicha normativa y en especial en la defensa de los derechos de las audiencias.

En la investigación se han utilizado fuentes de información secundarias y primarias. Entre las primeras lógicamente se ha partido de la recopilación y análisis de las disposiciones que inciden en la regulación publicitaria del sector televisivo. En cuanto a la información primaria, ha sido obtenida de las opiniones de expertos en derecho publicitario y profesionales procedentes del conjunto de agentes del sistema publicitario español (principales agencias 
publicitarias, centrales de medios y el censo completo de soportes televisivos de cobertura nacional cuya principal fuente de ingresos es la venta de espacio publicitario). El método de recogida de información fue a través de entrevistas no estructuradas, no ocultando en ningún momento a los entrevistados el motivo de la investigación. En total se realizaron 24 entrevistas. El guión de las entrevistas giraba en torno a dos ejes fundamentales: Por una parte, y bajo el objetivo de obtener una conceptualización correcta y común de las principales formas que puede adoptar la comunicación comercial en el medio televisivo, se procedió a caracterizar estas posibles tipologías, identificadas a priori por los investigadores a partir de la observación de la programación del espacio televisivo ${ }^{5}$. Y por otra, el eje de interpretación de la regulación respecto a las tipologías publicitarias identificadas, considerando la caracterización que se había realizado previamente, bajo el objetivo de valoración del grado de adecuación del marco legal a la realidad de la comunicación comercial del medio y la protección de las audiencias televisivas.

Con el fin de obtener una mayor fiabilidad en la investigación y reducir posibles interferencias personales en la interpretación de los criterios, en aquellos formatos comunes o con grandes similitudes entre las cadenas, se procedió previamente a definirlos y caracterizarlos de forma homogénea independientemente de su nomenclatura comercial en el canal televisivo en el que se insertaban.

\footnotetext{
${ }^{5}$ Para identificar y caracterizar las diferentes tipologías de comunicación comercial en el medio televisión se procedió previamente a registrar durante una quincena la programación de las cuatro cadenas generalistas de cobertura nacional que emitían en abierto: las dos cadenas públicas (TVE y La 2), Tele 5 y Antena 3 TV. Posteriormente se separó para su análisis todo el contenido dentro de la programación televisiva que no es estrictamente programa y que, independientemente de su consideración legal o comercial, es percibido por la audiencia como algo ajeno al objetivo inicial por el cual se encuentran delante de la televisión. Se ha llevado a cabo un visionado y registro a través de una ficha de explotación diseñada ad hoc de los siguientes datos: anunciante, producto/s, forma de presentación, objetivos, agente/s remunerado y forma de pago estimada, cuantificación del coste según tarifas del medio y agentes participantes en su gestión. Estos datos se contrastaron con investigaciones anteriores para verificar la posible aparición de nuevas formas de publicidad. Una descripción amplia y detallada de los formatos publicitarios en televisión se recoge en "Fundamentos básicos de la gestión publicitaria en televisión” de Reinares E. y Reinares P. (2003).
} 


\section{CLASIFICACIÓN LEGAL DE LAS FORMAS Y SUS IMPLICACIONES NORMATIVAS}

El análisis comparado de la Ley española junto el estudio de las prácticas comerciales de las cuatro cadenas generalistas españolas permite identificar un conjunto de formas publicitarias con contraprestación económica para el medio. Son mensajes comerciales televisados que los operadores emiten mediante contraprestación y por encargo y cuenta de terceros. Por ello quedan fuera del análisis de esta investigación los formatos cuyo objetivo primario no parte de la demanda de un anunciante externo al medio, como son las autopromociones de cadena y los avances de programación. Se analizan con más profundidad los que según datos de SOFRES tienen mayor presencia objetiva en la actual programación.

Para establecer una nomenclatura común que evite la confusión terminológica propia del mercado se ha utilizado las aportaciones bibliográficas previas de los autores de este artículo, en las que se realizan las justificaciones pertinentes.

\section{TABLA 1}

\section{Clasificación de formatos publicitarios en televisión}

\begin{tabular}{|l|l|l|}
\hline Formas publicitarias cuantificadas & $\begin{array}{l}\text { Formas publicitarias } \\
\text { cuantificadas pero no } \\
\text { restringidas } \\
\text { legalmente }\end{array}$ & $\begin{array}{l}\text { Formas publicitarias } \\
\text { descritas pero no } \\
\text { cuantificadas por ningún } \\
\text { organismo }\end{array}$ \\
\hline $\begin{array}{l}\text { - Spots } \\
\text { - Patrocinio televisivo(patrocinio } \\
\text { no solapado) }\end{array}$ & $\begin{array}{l}\text { - Autopromociones } \\
\text { programación }\end{array}$ & $\begin{array}{l}\text { - Barter } \\
\text { (microprogramas y } \\
\text { microespacios) }\end{array}$ \\
$\begin{array}{l}\text { - Teletiendas } \\
\text { - Telepromociones } \\
\text { internas(patrocinio solapado }\end{array}$ & - Cortinillas & $\begin{array}{l}\text { Product Placement } \\
\text { - Contenidos pagados } \\
\text { - Telepromociones } \\
\text { externas(patrocinio no solapado) }\end{array}$ \\
$\begin{array}{l}\text { - Sobreimpresiones } \\
\text { dentro del programa }\end{array}$
\end{tabular}

Si bien los formatos de la Tabla 1 tienen distintas implicaciones legales, ha sido necesario realizar una interpretación siguiendo el procedimiento descrito en la metodología de este trabajo que agrupa la normativa vigente con los procedimientos habituales del mercado. Una descripción del formato, su equiparación entre las diferentes prácticas comerciales de las 
cadenas y sus implicaciones normativas, ayuda a comprender como los agentes implicados realizan una sutil interpretación de la normativa que les permite explotar al máximo el potencial comercial de su programación.

A continuación se expone cuál es el tratamiento legal de las formas publicitarias, que además de estar contempladas total o parcialmente por la normativa española, es posible estudiar su desarrollo cuantitativo de forma objetiva a lo largo del tiempo por fuentes específicas como SOFRES o INFOADEX. Cada una de las siguientes figuras publicitarias forma parte fundamental de la estrategia de comercialización de las cadenas como soporte de comunicación de los anunciantes.

\section{Anuncios (spots)}

La Ley no define ni describe de forma específica esta forma publicitaria. Podría decirse que es una pieza de duración variable (generalmente entre 5 y 20”) destinada a promover marcas (anuncios corporativos), ofertas específicas (anuncios de producto) o conductas concretas. Generalmente se trata de un espacio de stock, que mantiene su monopolio enunciativo independientemente del canal y que se difunde de forma reiterada a través de diferentes soportes en el marco de una campaña.

Además de lo ya señalado en los criterios generales para la admisión de publicidad por televisión, la Ley establece que los anuncios publicitarios se emitirán de forma agrupada (es decir, en bloques ínter programas) y establece también una limitación temporal más estricta que la establecida de modo global ${ }^{6}$. En realidad, 12 minutos por hora de programación es un límite excesivo si se tiene en cuenta que el conjunto de cadenas, ha optimizado su espacio publicitario convencional hasta el limite de lo permitido no solo en los horarios de máxima audiencia (prime time). Agotada la posibilidad de crecimiento económico por medio de la comercialización de publicidad convencional (spots), la rentabilizacion de los 5 minutos complementarios que la ley permite para otros formatos (los que se describen a continuación),

\footnotetext{
${ }^{6}$ En este sentido, el tiempo dedicado por una cadena a spots no podrá superar el $15 \%$ del $20 \%$ global sobre el total diario de emisión, ni tampoco doce minutos de los diecisiete minutos globales autorizados por hora natural (Art. 13.2).
} 
es el verdadero elemento estratégico de posicionamiento de las cadenas frente a los anunciantes.

\section{Anuncios de televenta y Programas de televenta}

La Ley tampoco describe estas formas publicitarias, abordándose en posteriores documentos interpretativos más específicos.

Se trata de anuncios cuyo mensaje no sólo publicita un determinado producto, sino que además informa de una vía directa para su adquisición o contratación (llamada telefónica de voz, mensaje telefónico, señal a través del mando y del codificador en el caso de la televisión interactiva). A continuación se resumen las diferencias legales de ambos formatos.

TABLA 2

\section{Diferencias entre Anuncios y Programas de Televenta}

\begin{tabular}{l|l|l|} 
& Anuncios de televenta & Programas de televenta \\
\hline $\begin{array}{l}\text { Número máximo al día } \\
\begin{array}{l}\text { Duración mínima } \\
\text { máxima }\end{array}\end{array}$ & $\begin{array}{l}\text { No } \\
\text { Límite por hora natural }\end{array}$ & $\begin{array}{l}\text { El mismo que el resto de anuncios } \\
\text { publicitario: } 12 \text { minutos }\end{array}$ \\
\hline Límite por día & $\begin{array}{l}\text { El que afecta a la publicidad (en } \\
\text { todas sus formas) y anuncios de } \\
\text { televenta: 20 \% del tiempo de } \\
\text { emisión }\end{array}$ \\
\hline
\end{tabular}

REINARES, E. y REINARES, P. (2003); Pág. 235.

\section{Telepromociones}

Tampoco se encuentra en la Ley una definición de esta forma publicitaria. En sus criterios interpretativos para la aplicación de la norma, la Administración ${ }^{7}$ ofrece una interpretación reduccionista del concepto de telepromociones, considerando sólo como tales, los mensajes publicitarios de flujo que interrumpen un programa utilizando el mismo escenario, atrezzo, ambientación y /o vestuario (...) de dicho programa. La Ley incluye las telepromociones en el

\footnotetext{
${ }^{7}$ Véase el documento Criterios Interpretativos aplicados por la Subdirección General de Contenidos de la Sociedad de la Información en sus servicios de inspección y control. Madrid, 4 de octubre de 2001.
} 
cómputo global que limita la publicidad a diecisiete minutos por hora natural y al $20 \%$ del tiempo diario de emisión ${ }^{8}$. Podemos diferenciar dos tipologías:

- Telepromociones internas: En esencia, consisten en comunicaciones comerciales de un anunciante (ya sea de producto o de marca) realizadas dentro de un programa por el/los presentador/es habituales. La Ley obliga a tipificarlas con el rótulo "publicidad" sobreimpresionado en pantalla. Son programas de producción propia de las cadenas y se realizan en directo o falso directo.

La integración con los programas es alta, y al igual que en los patrocinios con caretas (o, incluso, en mayor medida puesto que, al ir dentro del programa, no hay fuga publicitaria por el zapping, coincidiendo la audiencia del programa y la audiencia de la publicidad) el anunciante puede seleccionar el público objetivo a impactar, en función del perfil de cada programa.

Son realizadas por el/los conductor/es habituales de los programas, con lo que ellos se erigen en prescriptores de los productos o servicios presentados. Se persigue la notoriedad inherente al vínculo del producto o servicio con las caras más conocidas de las cadenas. A pesar de que por ley las teleprociones internas (SOFRES los cuantifica denominándolos como patrocinios solapados) deben identificarse con la palabra publicidad, su elevada credibilidad por los prescriptores utilizados, plantea dudas sobre si determinados perfiles de consumidores, como amas de casa o jubilados reconocen que estos mensajes tienen claramente intencionalidad comercial persuasiva. Consideramos que si la ley busca proteger los derechos de los consumidores, para que estos reconozcan fehacientemente esta tipología de mensajes publicitarios, sería necesario exigir criterios de identificación más explícitos.

- Telepromociones externas: Son un formato no convencional de publicidad en televisión en el que personas y personajes de una cadena realizan la comunicación comercial del anunciante a partir de un desarrollo creativo basado en teleseries u otras situaciones

\footnotetext{
${ }^{8}$ Como en el caso de los publirreportajes, con el fin de evitar la inducción a error al espectador en cuanto al carácter publicitario de las telepromociones, durante su emisión deberá superponerse, permanentemente y de forma claramente legible, una transparencia con la indicación "publicidad".
} 
inherentes al papel habitual de cada rostro conocido en la cadena. Suelen ser piezas largas (normalmente de, al menos, 60 segundos) y emitidas en posición preferente del bloque publicitario. Consiguen una elevada asociación con el programa al que se vinculan creativamente, lo que repercute en un mayor impacto sobre la audiencia del programa y, con ello, del público objetivo del anunciante. Por la creatividad del formato la audiencia puede confundir este mensaje publicitario con los contenidos propios de la serie de ficción, pues la única diferenciación explicita es la sobreimpresión durante su emisión de la palabra "publicidad o telepromocion". Su eficacia para los objetivos comerciales del anunciante radica precisamente en la escasa diferenciación del formato publicitario con la teleserie a la que inmediatamente precede. Si bien en sentido estricto la ley se cumple al identificar la telepromocion como publicidad, todos los aspectos formales buscan que no se diferencie del propio programa en el que basa su creatividad. Seria necesario estudiar desde un punto de vista cualitativo como interpretan determinados perfiles sociodemográficos estos mensajes persuasivos.

\section{Sobreimpresiones}

La Ley establece (Art. 11.5) que en las “emisiones deportivas" podrán insertarse mensajes publicitarios y de

televenta utilizando transparencias o "cualquier otro tratamiento de la imagen" únicamente en aquellos momentos en que el desarrollo del acontecimiento retransmitido se encuentre detenido y siempre que no se perturbe la visión del acontecimiento ni se empleen transparencias que ocupen más de una sexta parte de la pantalla.

Se establece asimismo que esta publicidad consistirá exclusivamente, en textos escritos y/o el logotipo estático de la marca anunciante, sin otras imágenes reales o de animación ${ }^{9}$. De ser un formato de uso limitado por los operadores sorprende el crecimiento experimentado a partir

\footnotetext{
${ }^{9}$ En un ejemplo de ciertas ambigüedades que en determinados extremos caracterizan la Directiva de la Televisión sin Fronteras y sus respectivas trasposiciones nacionales, permite varias interpretaciones: La más laxa (a la que se acogen las cadenas), según la cual, el artículo 11.5 establece unas limitaciones para la publicidad por transparencias cuando se emite en el marco de retransmisiones deportivas que no regiría (o regiría parcialmente) para el resto de contenidos. Así se incluye también en este supuesto la insertada en los programas para promover la participación del espectador con el incentivo de un premio posible (906, SMS). Computa a efectos de la limitación temporal del $20 \%$ diario y de los diecisiete minutos por hora natural establecidos en el artículo 13.
} 
del año 2002. Las cadenas han encontrado una interesante fuente de ingresos en las sobreimpresiones que teóricamente buscan la participación de las audiencias en los programas. Esta permisividad ha saturado la programación de sobreimpresiones con finalidad comercial directa para la cadena (al recibir esta gran parte de los ingresos procedentes de la tarifación telefónica de la llamada del espectador) con la única restricción de no sobrepasar la limitación temporal asignada al conjunto de la publicidad. A pesar de su enorme desarrollo, es previsible que la aplicación de la nueva Directiva no permita continuar utilizando las sobreimpresiones con el objetivo de generar ingresos económicos para las cadenas directamente de sus audiencias.

\section{Patrocinios}

Es una modalidad en la que se mezclan los anuncios normales y los mensajes de patrocinio. Los spots de patrocinio deben computar como tiempo de publicidad según la Ley, dentro de otros formatos (tiempo máximo 17 minutos). Existen dos tipologías en los reportes de cuantificación que proporciona SOFRES: Spot de Patrocinio No Solapado: cuando aparece fuera de los programas, generalmente en los bloques de publicidad y Spot de Patrocinio Solapado: cuando se mezcla con la programación ${ }^{10}$. Esta clasificación, si bien es utilizada por el legislador en su función de control de los tiempos autorizados a las cadenas, simplifica en exceso las características de formatos claramente diferenciados en sus objetivos para el anunciante. Por ello, tal y como ya se ha expuesto, es mejor conceptuar como formatos diferenciados los patrocinios y las telepromociones internas e externas.

\subsection{Formas publicitarias conceptualizadas pero sin control cuantitativo de su desarrollo}

A continuación se describen como formatos publicitarios no convencionales, el product placement, los contenidos pagados dentro de los programas y el barter ${ }^{11}$. A pesar de ser evidente su utilización de forma consolidada no es posible determinar su nivel de desarrollo

\footnotetext{
10 Sofres considera como tales, por ejemplo, las menciones a productos dentro de los programas (que se identifican con la palabra "publicidad" o "promoción" en transparencia), y también las telepromociones.

11 Actualmente el formato y la denominación de barter esta en desuso. La evolución del formato son los microespacios con contenido publicitario, formato descrito de forma especifica por su creciente importancia.
} 
en las actuales programaciones. Por razones obvias derivadas de las características de estos tres formatos, hasta la fecha ningún organismo ha sido capaz de promover una metodología para cuantificar su desarrollo dentro de las distintas programaciones de forma periódica. Sobre estos formatos existen importantes implicaciones legales, pero lamentablemente con las actuales fuentes disponibles es imposible un acercamiento riguroso que permita determinar su importancia y evolución en las distintas cadenas de televisión. Existen no obstante, estudios ad hoc de tipo cualitativo que abordan puntualmente su desarrollo con una intencionalidad muy condicionada al agente que promueve el estudio (anunciante, medio o central).

\section{Barter (microespacios con contenido publicitario)}

En esencia, el bartering consiste en un acuerdo comercial basado en un intercambio entre la cadena televisiva y el anunciante, por medio del cual el anunciante entrega un programa ya producido a la cadena y a cambio la cadena pone a disposición del anunciante espacio publicitario u otras contraprestaciones. Se puede afirmar que el barter, en su origen, es un programa de televisión hecho a la medida del anunciante. Su objetivo primario es contactar con el target demandado por el anunciante para crear una imagen sin intención comercial directa. Esta tipología comparte muchos de sus ejes comunicacionales con los microprogramas, explicados a continuación, dado que son programas que nacen por y para el anunciante. No obstante, los microprogramas surgen en los departamentos comerciales de las cadenas (y están identificados y cuantificados como forma no convencional), mientras que los acuerdos barter no computan de modo alguno.

Como su propio nombre indica, los microprogramas consisten en espacios muy breves (entre 60 ” y 120"), con contenidos agrupados en torno a un eje temático común y concreto, adoptando un tono a medio camino entre lo divulgativo y lo informativo, con el objetivo de despertar el interés de perfiles de audiencia homogéneos y, por lo general, difíciles de impactar. Los contenidos son variados, pudiendo encontrar temáticas que van desde información financiera hasta hábitos saludables, pasando por ocio, belleza, motor, deportes, cine, comunicación, ecología, etc.

En función de si el conjunto del formato computa como publicidad, o si solo lo hacen las caretas de patrocinio que lo abren y lo cierran, reciben la denominación de microespacios o microprogramas. La doble denominación (microespacios y microprogramas) no es casual, dado que pueden llevar publicidad de dos maneras: 
- Microespacio: parte de los contenidos pueden ser publicitarios; al tener publicidad dentro, legalmente dejan de ser programas, para convertirse en un formato publicitario lejanamente emparentado con los antiguos publirreportajes.

- Microprograma: llevan la publicidad fuera del formato (que sólo tendrá contenido informativo) a modo de caretas de entrada y salida al espacio. A efectos legales es un patrocino común de un espacio de duración muy reducida confeccionado teniendo en cuenta los objetivos del anunciante patrocinador.

\section{Product Placement}

El "emplazamiento de producto" está perfectamente regulado legalmente. Pero la lógica comercial y la sofisticación que estas formas alcanzan, muy por delante del Regulador, están permitiendo a las cadenas facturar a cambio de variantes del mismo sin ser computado como formato publicitario.

Consiste en hacer aparecer el producto dentro de una serie televisiva o película, de acuerdo a una planificación comunicacional, sin alterar el desarrollo argumental de ésta.

La Ley 22/1999 es clara en cuanto a las limitaciones cualitativas a la publicidad, de manera que, atendiendo a su forma de presentación quedan prohibidas la publicidad y televenta encubiertas (Art. 9.2). Por ello la presentación de los bienes, los servicios, el nombre, la marca, las actividades o los elementos comerciales propios de un tercero se considerará intencionada y, por consiguiente, tendrá el carácter de publicidad encubierta, si se hiciese a cambio de una remuneración, cualquiera que sea la naturaleza de ésta. No tendrá esta consideración, la presentación que se haga en acontecimientos abiertos al público organizados por terceras personas y cuyos derechos de emisión televisiva se hayan cedido a un operador de televisión, cuando la participación de este último se limite a la mera retransmisión del evento y sin que se produzca una desviación intencionada para realzar el carácter publicitario". Por tanto, la publicidad se califica como encubierta cuando cumple los requisitos especificados en el Art. 3. d), presumiéndose, salvo que se demuestre lo contrario, que ésta se ha realizado a cambio de remuneración cualquiera que sea la naturaleza de ésta, siempre que haya quedado demostrado el propósito publicitario que en las emisiones ha tenido el operador de televisión.

En consecuencia, dado que un elemento esencial de la publicidad encubierta es la intencionalidad del operador, se entiende que ésta puede existir: en los programas de 
producción propia y en los programas de producción externa (el operador encarga la producción de un programa a un tercero reservándose todos los derechos sobre el programa terminado). Por el contrario, se considera que no puede existir responsabilidad del operador en las compras de derechos de emisión de obras ajenas (la denominada producción ajena), en cuya producción no se ha participado y cuyo titular es otro productor e incluso otro operador de televisión.

La gestión del product placement exige, que el producto o marca aparezca en una situación concreta y positiva que intensifique la imagen ya conocida por el público. La posibilidad de utilizar el product placement se justifica a partir del argumento de la necesidad (por exigencias del guión: es requerido por "razones artísticas") de la aparición del producto y, por lo tanto, no existiría ningún tipo de intencionalidad comercial. El soporte televisivo o cinematográfico no recibe contraprestación económica directa (para no caer en la ilegalidad). La contratación, gestión y pago del product placement se hace a través de productoras, aparentemente sin vinculación con el canal de televisión, que facilitan la introducción de los productos allí donde el guión lo posibilita.

\section{Contenidos pagados dentro del programa}

No es un formato publicitario en su sentido estricto, puesto que mientras en los anteriores existen procedimientos de gestión reconocidos, aunque no evidenciados, en este caso se trata de una forma de comunicación en televisión de la que nadie reconoce su utilización. Conceptualizando sobre este formato llegamos a la conclusión, que es posible introducir determinados contenidos de apariencia informativa dentro de las programaciones de las cadenas, con intencionalidad comunicativa previamente planificada. Nos encontraríamos ante el caso de publicidad en televisión más claramente sancionable por la obvia vulneración de los derechos de los consumidores, ya que éstos no conocen que se encuentran frente a mensajes con planteamientos claramente persuasivos. Así los agentes implicados, si bien reconocen que estas acciones son más o menos habituales en el medio, siempre argumentan desconocer elementos concretos de su gestión.

Los actuales contenidos televisivos desarrollan una gran variedad de programas de tipo magazine; éstos están compuestos de una gran amplitud de contenidos, lo que hace posible la sutil introducción de este formato publicitario. 
Demostrar que un reportaje en prime time sobre el preestreno de una película, o que una entrevista con un doctor pionero en una técnica estética concreta responde a un acuerdo entre un anunciante y la productora o el medio que incorpora dicho contenido, es en la práctica imposible. Para demostrarlo sería necesario contrastar la existencia de un acuerdo económico entre los agentes implicados. Esto transformaría los contenidos en un mensaje con intencionalidad comercial persuasiva, lo que está claramente prohibido por la legislación vigente. Precisamente ésta es la principal dificultad para abordar la descripción de este formato. Estos contenidos con apariencia informativa, son desarrollados de una forma oscura y un tanto compleja; un reportaje sobre un producto de belleza puede ser un acuerdo del departamento de Relaciones Públicas de dicho anunciante, encuadrado dentro de la negociación desarrollada a partir del presupuesto en publicidad convencional que dicho anunciante ha invertido en ese medio. No hay pago directo por el reportaje, pero es frecuente que los mensajes estén condicionados de una forma persuasiva hacia los intereses comunicacionales de dicho anunciante, respondiendo a una contraprestación por un acuerdo económico publicitario convencional.

\section{CONCLUSIONES}

A partir de los resultados de este estudio se pueden identificar múltiples aspectos, atendiendo a la defensa de los derechos de las audiencias, que debieran ser incorporados al ordenamiento jurídico que regula la actividad publicitaria en televisión en España.

La nueva Directiva Comunitaria de Servicios Audiovisuales aprobada el 24 de mayo de 2007 por los 27 países de la Unión Europea deberá ser adoptada por los mismos en sus legislaciones nacionales antes de 2010, sin embargo, el nuevo reglamento es un texto menos detallado y mas flexible que la norma actual española, coincidiendo e incluso potenciando, muchas de las limitaciones de la actual normativa reflejadas en este artículo.

Estas se resumen en las siguientes conclusiones:

Una de las carencias más llamativas de la actual normativa en España es que posibilita la utilización del product placement o emplazamiento de producto. Como ya se ha señalado, la Ley española prohíbe explícitamente la publicidad encubierta ${ }^{12}$. El emplazamiento de

\footnotetext{
${ }^{12}$ Véase el Artículo 1 de la Directiva 89/552 CEE modificada por la Directiva 97/34/CE y el Artículo 3 de la Ley 25/94, modificada por la Ley 22/99.
} 
producto no aparecía mencionado específicamente en la normativa de la televisión sin fronteras, Directiva 97/36/CE, referente en la elaboración de esta Ley. Por ello ha sido necesario interpretar su inclusión o no en el concepto de publicidad encubierta por televisión. Por un lado, hay que tener en cuenta que el emplazamiento de producto en televisión:

- Es una presentación de bienes, servicios, nombre, marca, actividad o elementos comerciales dentro de los programas.

- Es una presentación intencionada y remunerada, como lo demuestra la existencia de empresas especializadas en su venta y como lo atestiguan también el testimonio de productores, cadenas y anunciantes.

- Es una presentación que, frente al resto de formas publicitarias, no declara expresamente su naturaleza publicitaria a través de algún tipo de advertencia acústica u óptica, por lo que puede inducir al público a error en cuanto a tal naturaleza.

- Y por otro lado, cabe argumentar que el emplazamiento de producto en televisión no es formalmente publicidad televisiva, al menos cuando el programa contenedor ha sido realizado por una productora externa o ajena al operador de televisión. En tales casos, la remuneración directa del anunciante es a la productora y no a la cadena.

Paradójicamente, a causa de la pasividad de la Administración, la situación de ilegalidad (o, en el mejor de los casos, alegalidad) del emplazamiento no sólo no ha limitado hasta el momento su presencia en la pantalla, sino que incluso ha propiciado su desarrollo como una fuente de ingresos complementarios para productoras y/o cadenas cada vez más importante.

El problema de la falta de regulación adecuada para el emplazamiento de producto es su posible utilización indiscriminada y abusiva por parte de determinados anunciantes, productoras o canales. En efecto, si, como suele señalarse desde el sector, el emplazamiento de producto no es publicidad televisiva, ¿Cómo evitar que se convierta en un "coladero" para la mostración de marcas y productos prohibidos, para la difusión de mensajes comerciales engañosos o ilícitos, para la introducción de publicidad en los informativos, etc.?

Esta situación se puede ver corregida en la incorporación al ordenamiento jurídico español de la Directiva Comunitaria que el parlamento europeo ratificará en el mes de julio de 2007. El reconocimiento en la Directiva de esta forma de comunicación y su "autorización" con determinadas restricciones puede poner fin a la situación actual en la que es la propia cadena de televisión la que lo autoriza o no. Aunque en la nueva Directiva, el product placement se 
prohíbe como regla general, sin embargo, en las películas, series y espacios deportivos se pueden emplazar productos y marcas mediante la identificación con una señal especial al principio y al final del programa. Esta fórmula publicitaria estará vetada a determinados productos como tabaco o medicamentos. No obstante, cada estado puede optar por ser más restrictivo.

La protección del menor con relación a los contenidos publicitarios es también una de las líneas de preocupación más notorias de cara a una adecuación de la normativa a las prácticas habituales en las cadenas de televisión en España.

La actual adaptación de la normativa europea en materia de publicidad a la legislación española, presenta criterios permisivos que abren infinitas posibilidades a las cadenas de televisión para desarrollar formatos publicitarios sobre los que sería necesario plantear limitaciones. Precisamente, la necesidad de homologar modelos de negocio televisivo y realidades muy diferentes a nivel europeo ha planteado numerosos inconvenientes en la revisión de la Directiva de Televisión sin Fronteras. Una norma que se presupone definitiva, válida para mercados y audiencias cada vez más globales, necesariamente debe limitar muchos aspectos relacionados con la gestión publicitaria para evitar desigualdad en la protección de los intereses de las audiencias europeas; sin embargo, la nueva Directiva que se ratificará en julio de 2007, establece mínimas restricciones a la publicidad en los espacios infantiles, ya que, los programas para niños también podrán incluir publicidad si su duración es superior a los 30 minutos, a excepción de la colocación de productos que esta prohibida en los mismos. Con la excepción de la sugerencia de la elaboración de un código de conducta, que impida por ejemplo la emisión de anuncios de "comida basura" dirigidos a los niños, apenas se establecen restricciones en la publicidad destinada a esta audiencia.

Resulta sorprendente la permisividad con que los organismos implicados han tratado formatos publicitarios en creciente desarrollo y en teoría restringidos a situaciones muy concretas. Así las sobreimpresiones presentan un crecimiento proporcional a los ingresos que procuran a las cadenas. No basta con la necesidad de limitarlas dentro de los tiempos publicitarios permitidos. Las sobreimpresiones están por ley restringidas a eventos muy concretos; sin embargo, esta figura satura la programación con una finalidad muy diferente de lo que en principio la legislación regula. No cabe como argumento defensor la permisividad basada en que las sobreimpresiones que buscan la llamada del espectador tienen como objetivo la 
participación de las audiencias. Las restricciones deben limitar perfectamente tanto los espacios donde deben aparecer, como en especial la finalidad de estas, pues si de lo que se trata es de proteger los derechos de los consumidores, un derecho fundamental es la protección económica de estos. Los desorbitados ingresos de las cadenas por este método obligan a plantearse una limitación que ponga fin a este abuso en el fomento de las llamadas de teléfono impulsivas con grave coste económico para las audiencias.

Numerosas telepromociones, en especial aquellas que juegan con el desarrollo creativo de la teleserie que inmediatamente anteceden (telepromociones externas), buscan premeditadamente evitar que las audiencias identifiquen claramente el formato como algo persuasivo y pagado por el anunciante. Tampoco es suficiente con la limitación temporal o con la mínima identificación visual con la que los operadores argumentan cumplir la obligatoria identificación del mensaje publicitario. Es necesario contemplar una separación más evidente del programa para evitar confusiones, además de identificaciones visuales más claramente percibibles.

En definitiva, si bien existe una legislación razonablemente adecuada a los usos habituales de las cadenas con respecto a la publicidad y sus tipologías históricamente mas consolidadas, es conveniente la incorporación de elementos más pormenorizados que eviten la discrecionalidad favorable para las cadenas que se produce en la aplicación de formatos como los patrocinios, las telepromociones, sobreimpresiones y microespacios y microprogramas; sin embargo la nueva Directiva de servicios audiovisuales supone una liberalización mayor de la inserción de publicidad en la programación.

Respecto a los tiempos máximos, aunque diecisiete minutos por hora de programación parece un volumen de publicidad ya asumido por el mercado español, estas son cifras muy por encima de la media del resto de televisiones europeas.

Se debe tener en cuenta que las cadenas están continuamente al límite de la saturación publicitaria permitida. Este volumen de publicidad, ya excesivo en si mismo, se vería sobrepasado, si como es lógico dentro de los tiempos máximos computaran formatos actualmente no sometidos a restricción temporal alguna. Así no computan como publicidad las autopromociones del canal y los avances de programación. Si bien estas dos tipologías no son mensajes pagados por un agente ajeno al medio, claramente contribuyen al aumento de la saturación publicitaria. A pesar del esfuerzo de las cadenas por autorregular este formato, su 
cuantificación evidencia que de forma frecuente se sobrepasaría por mucho los tiempos máximos de interrupción autorizados a lo largo de la programación para el bloque publicitario. De incluir su cómputo junto con los formatos publicitarios se podría comprobar, tal y como indican recientes estudios ${ }^{13}$, que más de la cuarta parte del tiempo medio diario de emisión corresponde a acciones comerciales tanto del anunciante como de la propia cadena. Así parece evidente la necesidad de una reducción de los tiempos máximos permitidos por ley que incluya además en los cómputos una delimitación aun más estricta de lo que se denomina mensaje publicitario; sin embargo, en la nueva Directiva Comunicaría que tendrá que adaptarse al marco jurídico español antes del año 2010, se podrán superar incluso las tres horas máximas de publicidad diaria que se permiten en la actualidad, ya que aunque se mantiene el límite máximo de publicidad en un $20 \%$ de la emisión, lo que equivale a los 12 minutos de publicidad por hora que rigen en la actualidad, en este computo no se incluye el product placement, que permitirá colocar productos publicitarios en todos los programas salvo en los informativos, los programas infantiles, los documentales y los programas de asesoramiento sin computar en la cuantificación, ni se incluyen las telepromociones, para las que tampoco se establece un tope máximo como sucede en la actualidad.

En definitiva, esto supone una mayor saturación publicitaria aún que la experimentada con la actual legislación vigente en perjuicio de anunciantes y sobre todo las audiencias. La nueva Directiva además resulta mas permisiva en cuanto a los cortes publicitarios. Únicamente en el caso de películas, telefilmes, programas para niños e informativos, sólo podrán insertarse cortes publicitarios una vez cada 30 minutos, y en los programas religiosos ninguno. Para el resto de programas se liberaliza por completo, aunque, como se ha señalado, se mantiene el límite máximo de 12 minutos de anuncios por hora. En definitiva, el nuevo reglamento suprime la obligación actual de dejar un mínimo de 20 minutos entre cada interrupción publicitaria y también permitirá detener temporalmente las películas cada 30 minutos para emitir publicidad, en lugar de los 45 minutos exigidos en la actualidad.

\footnotetext{
${ }^{13}$ Las principales conclusiones de una investigación con este objetivo principal financiada por el Ministerio de Sanidad y Consumo se recogen en: Publicidad no convencional y los derechos de los consumidores, de REINARES LARA, P. Instituto Nacional de Consumo, Madrid. (2003).
} 
Aunque no se ha abordado de forma específica en este estudio ${ }^{14}$, el bajo coste económico de las sanciones por el incumplimiento de la normativa no parece un elemento disuasorio suficiente para que las cadenas olviden regularmente la normativa. Está aceptado por el mercado, que las sanciones económicas de producirse, son siempre de menor cuantía que el beneficio económico obtenido al incumplir algún precepto. Probablemente, tanto el hecho de que los operadores públicos participen a partes iguales en el incumplimiento reiterado de aspectos como tiempos máximos, contraprogramación o product placement, ha hecho difícil hasta ahora que alguna cadena se erija como parte interesada en el cumplimiento estricto de la normativa por el resto de operadores.

Es previsible el desarrollo de las nuevas tecnologías en los modelos de televisión generalistas (la próxima y obligatoria digitalización de las emisiones abre las puertas a nuevas formas publicitarias en desarrollo en modelos televisivos restringidos de pago). Sin estar todavía claro que tipo de formatos publicitarios permitirá la interactividad que ya se está comprobando en las cadenas de pago, parece probable una cierta adaptación de procedimientos habituales de Internet, como son banners, pantalla compartida, mensajes personalizados o la posibilidad de interactuar con el mensaje publicitario. Esto facilitará la compra impulsiva por la mayor eficacia de mensajes publicitarios muy segmentados.

En la interpretación de la nueva Directiva en los países europeos, las normas publicitarias se aplicarán a la televisión convencional y a otros servicios audiovisuales sea cual sea el sistema de transmisión pero no afectará a Internet.

Se tiende a analizar las formas publicitarias desde aspectos cuantitativos y legales. Sorprende la poca importancia que los distintos agentes implicados dan a analizar rigurosamente los efectos de estas acciones comunicativas sobre las audiencias. Desde un punto de vista persuasivo y de protección de los derechos de los consumidores (que en definitiva es el propósito de la normativa vigente) no es lo mismo un spot convencional que un spot de

\footnotetext{
14 Sobre la inspección, sanción y control en el ámbito de la publicidad televisiva sería necesario desarrollar un capítulo específico para dotar de la profundidad adecuada a un tema fundamentalmente complejo, tanto por la multiplicidad de organismos relacionados, como por las evidentes carencias operativas de la normativa en este importante aspecto. Por otra parte el reciente cambio de gobierno hace previsible una profunda revisión de la aplicación ejecutiva de determinadas competencias que invalidaran una descripción de los actuales procedimientos.
} 
patrocinio solapado. El hecho de que habitualmente las fuentes no incorporen como formato publicitario las autopromociones, los avances de programación, y las cortinillas revela la necesidad de investigar considerando fuente primaria las audiencias. Como punto de partida básico, es necesario contrastar científicamente si éstas consideran la comunicación comercial de la cadena, como programación (como determina la legislación y los operadores) o como espacio publicitario (como se pretende en algunos estudios cualitativos promovidos por asociaciones de consumidores para evidenciar la saturación del medio ${ }^{15}$ ).

\section{BIBLIOGRAFIA}

- ARTHUR ANDERSEN Y UNIVERSIDAD DE NAVARRA 2000, El futuro de la televisión en España, Arthur Andersen y Universidad de Navarra.

- ASOCIACIÓN ESPAÑOLA DE ANUNCIANTES 2006, Memoria anual 2005. Informe de Actividades 2005-2006, Asociación Española de Anunciantes.

- ASOCIACIÓN NACIONAL DE ANUNCIANTES 1993, Manual de legislación de publicidad, Deusto, Bilbao.

- BEERLI PALACIO, A. Y MARTÍN SANTANA, J. 1999, "Procedimiento de evaluación de la eficacia de anuncios publicitarios", Revista Española de Investigación de Marketing ESIC, n $^{\circ}$. 1, Vol. 3, pp. 37-61.

- BIOSCA, I. 2002, "El futuro de la televisión”, Documentación de las jornadas "La televisión: modelo de negocio”, Publiespaña-Universidad Europea de Madrid, Villaviciosa de Odón, 9 y 10 de julio.

- BORREL, L. 2002, “La visión estratégica de la televisión”, Documentación de las jornadas "La televisión: modelo de negocio", Publiespaña-Universidad Europea de Madrid, Villaviciosa de Odón, 9 y 10 de julio.

- CARAT CRYSTAL Y BIRD \& BIRD 2002, "Etude Sur Le Développement Des Nouvelles Techniques Publicitaires", Rapport Final avril, Carat Crystal y Bird \& Bird.

- CIA MEDIALAB 2003, Sensor Ola 2a : Verano 2003. Internacional, CIA MediaLab.

\footnotetext{
${ }^{15}$ La AUC destaca como uno de los" lobbys" mas reivindicativos sobre la descontrolada estrategia comercial del mercado publicitario en televisión en España y sus repercusiones sobre los consumidores.
} 
- COMISIÓN DEL MERCADO DE LAS TELECOMUNICACIONES Y CONSELL DE LÁUDIOVISUAL DE CATALUNYA 2002, La televisión digital terrenal en España, Comisión del Mercado de las Telecomunicaciones.

- EUROPEAN BROADCASTING UNION Y UNION EUROPEENNE DE RADIO-TELEVISION 2004, EBU preliminary views on regulatory aspects of new advertising techniques, European Broadcasting Union y Union Europeenne de Radio-Television.

- GABINETE DE ESTUDIOS DE LA COMUNICACIÓN AUDIOVISUAL 2003, Anuario de la televisión 2003, Gabinete de Estudios de la Comunicación Audiovisual.

- GARCÍA, L. Y LLOPIS, L. 2002, “La aportación de las televisiones privadas al mercado y gestión de la televisión", Documentación de las jornadas "La televisión: modelo de negocio”, Publiespaña-Universidad Europea de Madrid, Villaviciosa de Odón, 9 y 10 de julio.

- GONZÁLEZ COMAS, O. 2002, "La comercialización de la televisión: sus diferentes perspectivas", Documentación de las jornadas "La televisión: modelo de negocio", Publiespaña-Universidad Europea de Madrid, Villaviciosa de Odón, 9 y 10 de julio.

- INFOADEX 2007, Estudio Infoadex de la Inversión Publicitaria en España 2006, Infoadex, Madrid.

- LE BLANC WICKS, J. y ABERNETHY, A. 2001, "Effective Consumer Protection or Benign Neglect? A model of Television Informercial Clearance", Journal of Advertising, Vol. 30, No. 1. pp. 41-54.

- LEY 22/1999 DE 7 DE JUNIO DE MODIFICACIÓN DE LA LEY 25/1994 DE 12 DE JULIO, por la que se incorpora al Ordenamiento Jurídico Español la Directiva 89/552/CEEE, sobre la coordinación de disposiciones legales, reglamentarias y administrativas de los Estados miembros, relativas al ejercicio de actividades de radiodifusión televisiva.

- LEY 25/1994 DE 12 DE JULIO, que incorpora al ordenamiento jurídico español la coordinación de disposiciones legales, reglamentarias y administrativas de los Estados miembros, relativas al ejercicio de actividades de radiodifusión televisiva.

- $\quad$ LEY 34/1988 DE 11 DE NOVIEMBRE, General de la Publicidad. 
- MEDIAEDGE: CÍA 2006, Panorama de la Televisión en España 2005, Mediaedge: Cía, Madrid.

- OlARTE PASCUAL, C., REINARES LARA, E. Y SACO VÁZQUEZ, M. 1993, “El mercado televisivo español: sector en conflicto", Actas del V Encuentro de Profesores Universitarios de Marketing, Sevilla, Octubre, pp. 469-475

- PERALES ALBERT, A. 2003, El tratamiento legal de la publicidad en televisión”, Informe interno Asociación de Usuarios de la Comunicación.

- PRODUCCIÓN PROFESIONAL 2002, "El gobierno reabre la caja de los truenos", Producción Profesional, $\mathrm{n}^{\circ}$ 35, diciembre, pp. 4-5.

- REINARES LARA, P. 2003, Publicidad no convencional y los derechos de los consumidores, Instituto Nacional de Consumo, Madrid.

- REINARES LARA, P. Y CALVO FERNÁNDEZ, S. 1999, Gestión de la Comunicación Comercial, McGraw-Hill, Madrid.

- REINARES LARA, P. Y FERNÁNDEZ RODRÍGUEZ, R. 1996, “Tendencias globales del desarrollo del medio televisivo español como soporte publicitario", Actas del X Congreso Nacional y VI Congreso Hispano-Francés de la Asociación Europea de Dirección y Economía de la Empresa AEDEM), Granada, junio.

- REINARES, E. Y REINARES, P. 2003, Fundamentos básicos de la gestión publicitaria en televisión, Esic Editorial, Madrid.

- SÁNCHEZ TABERNERO, A. 2000, "Competencia entre la televisión y otros medios" en El futuro de la televisión en España, Arthur Andersen y Universidad de Navarra, Capítulo 5, pp. 67-85.

- SUBDIRECCIÓN GENERAL DE CONTENIDOS DE LA SOCIEDAD DE LA INFORMACIÓN 2001, Criterios interpretativos de emisiones publicitarias, Subdirección General de Contenidos de la Sociedad de la Información Madrid.

- T. N. S. A. M. 2006, Anuario de audiencias de televisión 2005, Taylor Nelson Sofres A.M., Madrid.

- UNIÓN DE TELEVISIONES COMERCIALES ASOCIADAS 2002, "El mercado publicitario español y los efectos de la política comercial de RTVE”, Dossier de prensa presentando por la Unión de Televisiones Comerciales Asociadas, marzo. 
- WHEELER, M. (2004): "Supranational Regulation: Television and the European Union", European Journal of Communication, Vol. 19, Iss. 8, pp. 349-369. 